\title{
Effect of population-based training programs on bystander willingness to perform cardiopulmonary resuscitation
}

\author{
CHIEN CHENG-YU ${ }^{1}$, WENG YI-MING ${ }^{2}$, HSU SHOU-CHIEN ${ }^{1}$, KUO CHAN-WEI $^{2}$, CHAOU CHUNG-HSIEN ${ }^{3}$
}

\author{
${ }^{1}$ Department of Emergency Medicine, Chang Gung Memorial Hospital, Keelung, Taiwan \\ ${ }^{2}$ Department of Emergency Medicine, Chang Gung Memorial Hospital, Linkou, Taiwan \\ ${ }^{3}$ Department of Emergency Medicine and Medical Education, Chang Gung Memorial Hospital \\ and Chang Gung University College of Medicine, Taoyuan, Taiwan
}

Corresponding author:

Chung-Hsien Chaou

Department of Emergency Medicine

Chang Gung Memorial Hospital

No.5, Fusing St., Gueishan Township, Taoyuan County 333, Taiwan (R.O.C.)

Phone: 886-3-3281-200 ext. 2143

Fax: 886-3-3287715

E-mail:shien@url.com.tw

\section{ABSTRACT}

Objective. This study was performed to determine the factors related to unwillingness of bystanders to perform cardiopulmonary resuscitation (CPR), and improvement of willingness among the lay public after CPR training.

Design. Retrospective design

Methods. We collected questionnaires received from laypersons attending $\mathrm{CPR}$ training courses implemented by the CPR Improvement Program of Chang Gung Memorial Foundation. Pre- and posttraining questionnaires were given to participants attending CPR training courses between September 2013 and January 2014.

Results. Among the 401 respondents at pre-training, higher educational level (odds ratio, 3.605; 95\% confidence interval [CI], $3.055-8.284$ ) and previous CPR training (odds ratio, 1.754; 95\% CI, $1.049-2.932$ ) were significantly associated with willingness to perform bystander CPR. Significant improvements in willingness to perform conventional $\mathrm{CPR}$ and hands-only CPR on a stranger were observed after training $(\mathrm{P}=0.016$ and $\mathrm{P}<0.0001$, respectively). Approximately half of the respondents claimed that fear of doing further harm was the primary reason for their lack of willingness to admin- ister conventional CPR on a stranger.

Conclusions. We showed that CPR training significantly increased the rate of willingness to perform CPR on strangers as well as acquaintances among the lay public. This study also showed that fear of doing further harm was the most significant barrier after training. This concern should be addressed in future training programs.

Key words: cardiopulmonary resuscitation, cardiopulmonary resuscitation training, bystander willingness

\section{INTRODUCTION}

Out-of-hospital cardiac arrest (OHCA) has become a global public health problem. The incidence of OHCA varies between countries, (1) but the global incidence is between 50 and 60 per 100,000 person-years worldwide. (2) The survival rate for OHCA is generally low, ranging from $5 \%$ to $10 \%$. $(3,4)$ A nationwide population-based study using the Taiwan $\mathrm{Na}$ tional Health Insurance Research Database (NHIRD) showed that the overall incidence rate of OHCA was 51.1 per 100,000 persons during the period from 2000 to 2012. (5) Wang also reported that the overall 1-day, 30-day, and 180-day mortality rates of all OHCA patients were $81.3 \%$, $89.1 \%$, and $90.2 \%$, respectively. These findings indicate the importance of early resuscitation. It is generally acknowledged that immediate cardiopulmonary resuscitation (CPR) can increase the chance of survival after OHCA. (6-9)

However, studies have shown that not all people are willing to perform CPR on strangers when they witness OHCAs. $(10,11)$ Therefore, CPR training courses for the lay public have been increasingly emphasized as a means of improving these low bystander CPR rates. The reasons why people are unlikely to administer CPR have also been examined, and include fear of doing CPR incorrectly, being physically unable to perform CPR, fear of harming the individual, fear of transmittable diseases, belief that the person was dead, and legal liability. Many studies have indicated that mouth-to-mouth ventilation is an important factor in the public's unwillingness to perform bystander CPR, particularly on a stranger. (12-15) Although not mentioned in many studies, fear of legal consequences has also been reported to be a factor rendering respondents less likely to perform bystander CPR on strangers.

In Taiwan, mouth-to-mouth ventilation and legal concerns seem to be significant barriers to performing bystander CPR. However, there have been few studies regarding Taiwanese attitudes toward CPR. It remains unclear why laypersons are unlikely to engage in CPR even after taking many CPR courses. Therefore, this study was performed to investigate the factors 
affecting layperson willingness to perform CPR on a stranger, family member, or friend as well as the reasons for not performing bystander CPR before and after attending CPR training.

\section{METHODS}

\section{Study design}

This study was performed to examine whether attending CPR courses would improve willingness to perform bystander $\mathrm{CPR}$ and related factors using a researcherconducted questionnaire from the IGOGO program in Taiwan. The IGOGO program was supported by Chang Gung Memorial Hospital (CGMH) with the aim of introducing and improving CPR skills in laypersons. In this program, participants were asked to complete an anonymous questionnaire before and after a CPR training course to ascertain their willingness to perform CPR.

In the present study, we extracted data from these questionnaires regarding participant demographics, willingness to perform CPR, and reasons for not performing CPR. The factors associated with pre-course willingness to perform $\mathrm{CPR}$, as well as the effects of the training program in the general population in Taiwan, were analyzed. The study was approved by the Institutional Review Board (IRB) of CGMH. The requirement for informed consent was waived by the IRB.

\section{Study population and CPR course}

The participants were recruited from among the general population, and were basically laypersons. Participants less than 20 years of age were excluded. A total of 20 standard 90-minute CPR training courses were held during the study period. Each course consisted of a 60-minute CPR teaching video with practice, 20 minutes of automated electrical defibrillator operation, and a 10-minute discussion with regard to the legal issues associated with bystander CPR in Taiwan. All of the CPR courses were undertaken in a small-group training setting with teacher-to-student and manikin-to student-ratios of less than $1: 15$ and $1: 3$, respectively.

\section{Questionnaire}

Pre-training and post-training questionnaires were given to participants who attended CPR training courses recruited by IGOGO between September 2013 and January 2014. A period of 10 minutes was scheduled for the participants to complete the questionnaire. In the program, a 22item questionnaire with closed questions was used to determine participant demographics, previous CPR training and experience, medical history, willingness to perform CPR, and reasons for lack of willingness to perform CPR. The questionnaire was based on previous studies conducted in other countries. The first section elicited responses regarding each participant's age, gender, education level, religion, occupation, past clinical experience, medical history, as well as previous CPR training. The second part of the questionnaire was related to willingness to perform traditional CPR or chest compression-only CPR on a stranger, family member, or acquaintance, and reasons for not performing CPR. All participants were instructed to complete the self-administered questionnaires in approximately 10 minutes before and after the CPR training courses.

\section{Data analysis}

The data collected were entered into an electronic database for analysis. Participants that returned completed questionnaires were defined as respondents. All returned questionnaires were included in the analysis. Statistical analysis was conducted using the SPSS for Windows software (SPSS Inc., Chicago, IL, USA). Descriptive analyses were performed on all variables. Continuous variables are presented as means and standard deviations, while categorical variables are summarized as frequencies and percentages. The paired t-test was used to compare continuous variables before and after CPR training. McNemar's test was used for comparison of categorical variables before and after CPR courses. Univariate and multivariate logistic regression models were used to identify potential factors influencing pre-course willingness to perform CPR. The results are presented as odds ratios (OR) and 95\% confidence intervals $(\mathrm{CI})$. In all analyses, $\mathrm{P}<0.05$ was taken to indicate statistical significance.

\section{RESULTS}

\section{Demographics}

A total of 638 pre-training questionnaires were collected, of which 401 were completed, giving a response rate of $62.9 \%$. Post-training questionnaires were issued to 355 (88.5\%) participants, of whom 227 responded, giving a response rate of $63.9 \%$ (227/355). Of the 401 respondents, 153 (38.2\%) were male and the mean (SD) age was $49.2(10.3)$ years in all respondents (table 1). More than half of the subjects were married, held at least a high school diploma, had taken CPR training before, and specified Buddhism or folk beliefs as their religion. Approximately half of the respondents were employees of the military or government.

\section{Factors affecting CPR willingness prior to attending CPR courses}

Among the 401 respondents, 124 (30.9\%) were willing to perform bystander CPR. Comparisons of demographics according to willingness to perform bystander CPR were performed. In total, 42 of the 124 respondents $(33.9 \%)$ who were willing to perform bystander CPR, and 111 of the 277 respondents (40.1\%) who were unwilling to perform CPR, were male. The results indicated statistically significant differences in age, education level, marital status, history of chronic illness, living with the elderly, and previous CPR training between the two groups (table 2). Therefore, multivariate analyses were used to evaluate the impact of these underlying factors on CPR willingness (table 3 ). On multivariate analysis, factors impacting bystander CPR willingness were education level and previous CPR training $(\mathrm{P}<0.05)$. Odds ratios revealed that respondents with at least a high school diploma, who had taken CPR training previously, were most willing to perform bystander CPR.

\section{Changes in CPR willingness before and after CPR courses}

A total of 227 (63.9\%) questionnaires were returned after CPR training courses. Among them, 90 (39.6\%) respondents expressed willingness to perform bystander CPR. As shown in table 4, McNemar's test indicated significant changes in $\mathrm{CPR}$ willingness after training in participants who returned both pre- and post-training questionnaires. Prior to CPR training, $83(36.6 \%)$ and $154(67.8 \%)$ of the 227 respondents were willing to provide a stranger with conventional or hands-only $\mathrm{CPR}$, respectively. More respondents were willing to perform either conventional or hands-only CPR for acquaintances before taking the CPR training course.

After the CPR course, significant increases 
in the proportions of participants willing to perform conventional and hands-only CPR on a stranger or acquaintance were observed. An especially marked increase was observed in willingness to perform hands-only CPR on a stranger.

\section{Main reasons for unwillingness to per- form CPR before and after training}

In the initial evaluation, unwillingness to give mouth-to-mouth ventilation, followed by fear of legal issues, accounted for $80 \%$ of the respondents that were not willing to resuscitate a stranger $(67 / 144,46.5 \%$ and $53 / 144,36.8 \%$, respectively), while fear of causing further harm was the major reason for not performing bystander CPR after training (66 of the 137 respondents, $48.2 \%$, that were unwilling to perform bystander CPR). After training, only 3 (2.19\%) of the 137 respondents reported fear of legal issues. However, the proportion of respondents who were afraid of performing CPR incorrectly increased by almost double compared to before training $(5.56 \%$ vs. $11.0 \%$, respectively). In addition, a few people ( 8 of the 137 respondents, 5.84\%) reported that they were unwilling to perform cardiac compression after attending CPR training.
On the other hand, $23(76.7 \%)$ and 14 (56.0\%) of the respondents reported fear of causing further harm as the main reason for their unwillingness to perform CPR on an acquaintance before and after training, respectively. Similar to unwillingness to perform bystander CPR, the proportion of respondents reporting fear of performing CPR incorrectly doubled after training, from $2(20.0 \%)$ to $10(40.0 \%)$ respondents, among those who were not willing to perform CPR on an acquaintance. The results are presented in table 5 .

Table 1. Characteristics of respondents.

Demographics of 401 respondents

\begin{tabular}{|c|c|}
\hline Age in years $($ Mean $\pm S D)$ & $49.19 \pm 10.3$ \\
\hline \multicolumn{2}{|l|}{ Gender (N,\%) } \\
\hline Male & $153(38.2 \%)$ \\
\hline \multicolumn{2}{|l|}{ Educational level $(\mathrm{N}, \%)$} \\
\hline$\leq$ High School & $117(29.2 \%)$ \\
\hline$>$ High School & $284(70.8 \%)$ \\
\hline \multicolumn{2}{|l|}{ Marital status $(\mathrm{N}, \%)$} \\
\hline Single or divorced & $101(25.2 \%)$ \\
\hline Married & $300(74.8 \%)$ \\
\hline \multicolumn{2}{|l|}{ Religion $(\mathrm{N}, \%)$} \\
\hline None & $118(29.4 \%)$ \\
\hline Buddhism or folk beliefs & $276(68.8 \%)$ \\
\hline Christianity or Catholicism & $7(1.8 \%)$ \\
\hline \multicolumn{2}{|l|}{ Occupation $(\mathrm{N}, \%)$} \\
\hline Military and government & $152(37.9 \%)$ \\
\hline Farmers/fishermen, labors or business & $136(33.9 \%)$ \\
\hline Self-employed/merchants & $40(9.98 \%)$ \\
\hline Services & $72(18.0 \%)$ \\
\hline Students & $1(0.25 \%)$ \\
\hline Previous CPR training $(\mathrm{N}, \%)$ & $213(53.1 \%)$ \\
\hline
\end{tabular}

$\mathrm{CPR}$, cardiopulmonary resuscitation; $\mathrm{N}$, number; $\mathrm{SD}$, standard deviation.

Table 2. Respondents demographics by pre-course willingness.

\begin{tabular}{llll}
\hline Characteristic & Willing to CPR $(\mathbf{n}=\mathbf{1 2 4})$ & Unwilling to CPR $(\mathbf{n}=\mathbf{2 7 7})$ & P-Value \\
\hline Age (years) & $45.6(9.6)$ & $50.8(10.2)$ & $<0.001^{\star}$ \\
\hline Male gender & $42(33.9 \%)$ & $111(40.1)$ & 0.267 \\
\hline Educational level & & $155(56.0 \%)$ & $<0.001^{\star}$ \\
\hline$\leq$ High School & $25(20.2 \%)$ & $122(44.0 \%)$ & $0.0015^{\star}$ \\
\hline$>$ High School & $99(79.8 \%)$ & & \\
\hline Marital status & & $57(20.6 \%)$ & \\
\hline Single or divorced & $44(35.5 \%)$ & &
\end{tabular}




\begin{tabular}{|c|c|c|c|}
\hline Married & $80(64.5 \%)$ & $220(79.4 \%)$ & \\
\hline Medical/paramedical personnel & $16(12.9 \%)$ & $24(8.66 \%)$ & 0.190 \\
\hline Previous chronic disease & $17(13.7 \%)$ & $84(30.3 \%)$ & $<0.001^{\star}$ \\
\hline Previous major disease & $2(1.61 \%)$ & $8(2.89 \%)$ & 0.730 \\
\hline Living with elderly (>65y/o) & $55(43.4 \%)$ & $85(30.7 \%)$ & $0.008^{*}$ \\
\hline $\begin{array}{l}\text { Experience of performing CPR in } \\
\text { real life }\end{array}$ & $2(1.61 \%)$ & $5(1.81 \%)$ & $>0.999$ \\
\hline Previous CPR training & $87(70.2 \%)$ & $126(45.5 \%)$ & $<0.001^{\star}$ \\
\hline \multicolumn{4}{|l|}{ Last CPR learning time } \\
\hline None & $37(29.8 \%)$ & $151(54.5 \%)$ & \\
\hline$<1$ year & $12(9.68 \%)$ & $13(4.69 \%)$ & \\
\hline $1 \sim 2$ years & $14(11.3 \%)$ & $14(5.05 \%)$ & \\
\hline $2 \sim 5$ years & $27(21.8 \%)$ & $42(15.2 \%)$ & \\
\hline$>5$ years & $28(22.6 \%)$ & $41(14.8 \%)$ & \\
\hline Unclear & $6(4.84 \%)$ & $16(5.78 \%)$ & \\
\hline \multicolumn{4}{|l|}{ Type of CPR course } \\
\hline Traditional & $40(46.0 \%)$ & $66(52.4 \%)$ & \\
\hline Hand-Only CPR & $47(54.0 \%)$ & $60(47.6 \%)$ & \\
\hline \multicolumn{4}{|l|}{ Memory of last CPR course } \\
\hline Very clear & $12(13.8 \%)$ & $8(6.35 \%)$ & \\
\hline Clear & $17(19.5 \%)$ & $23(18.3 \%)$ & \\
\hline Normal & $28(32.2 \%)$ & $46(36.5 \%)$ & \\
\hline Unclear & $29(33.3 \%)$ & $49(38.9 \%)$ & \\
\hline Very Unclear & $1(1.15 \%)$ & $0(0.0 \%)$ & \\
\hline
\end{tabular}

Table 3. Potential factors that affecting the pre-course willingness of CPR.

\begin{tabular}{lll}
\hline Factors & Multivariate analysis & \\
\hline Level of education & Odds ratio & 95\% CI \\
\hline Male sex & $3.605^{\star}$ & $2.019 \sim 6.438$ \\
\hline Marital status & 1.241 & $0.760 \sim 2.029$ \\
\hline History of Chronic illness & 0.643 & $0.373 \sim 1.106$ \\
\hline Living with elderly & 0.617 & $0.327 \sim 1.167$ \\
\hline Previous CPR training & 1.098 & $0.670 \sim 1.800$ \\
\hline
\end{tabular}

CPR, cardiopulmonary resuscitation.

* Statistically significant

Table 4. Willingness to perform CPR before and after training.

\begin{tabular}{llll}
\hline Willingness & Before training $(\mathbf{N}=\mathbf{2 2 7})$ & After training $(\mathbf{N}=\mathbf{2 2 7})$ & P-value \\
\hline Willing to perform CPR on a stranger & $83(36.6 \%)$ & $90(39.7 \%)$ & $0.016^{*}$ \\
\hline Willing to perform hands only CPR on a stranger & $154(67.8 \%)$ & $191(84.1 \%)$ & $<0.0001^{*}$ \\
\hline Willing to perform CPR on a known person & $197(86.8 \%)$ & $202(89.0 \%)$ & 0.063 \\
\hline Willing to perform hands only CPR on a known person & $200(88.1 \%)$ & $212(93.4 \%)$ & $<0.0001^{*}$
\end{tabular}

$\mathrm{CPR}$, cardiopulmonary resuscitation; $\mathrm{N}$, number of respondents

* Statistically significant 
Table 5. Reasons for not to perform standard CPR.

\begin{tabular}{lll}
\hline Reasons & Before training & After training \\
\hline Most important reason of not performing CPR on a stranger & $\mathrm{N}=144$ & $\mathrm{~N}=137$ \\
\hline Afraid of doing further harm & $16(11.1 \%)$ & $66(48.2 \%)$ \\
\hline Afraid of doing CPR incorrectly & $8(5.56 \%)$ & $15(11.0 \%)$ \\
\hline Afraid of legal issues & $53(36.8 \%)$ & $3(2.19 \%)$ \\
\hline Unwilling to give mouth-to-mouth breaths & $67(46.5 \%)$ & $45(32.9 \%)$ \\
\hline Unwilling to perform cardiac compression & $0(0.0 \%)$ & $8(5.84 \%)$ \\
\hline Most important reason of not performing CPR on a known person & $\mathrm{N}=30$ & $\mathrm{~N}=25$ \\
\hline Afraid of doing more harm & $23(76.7 \%)$ & $14(56.0 \%)$ \\
\hline Afraid of doing CPR incorrectly & $2(20.0 \%)$ & $10(40.0 \%)$ \\
\hline Afraid of legal issues & $0(0.0 \%)$ & $0(0.0 \%)$ \\
\hline Unwilling to give mouth-to-mouth breaths & $1(3.33 \%)$ & $0(0.0 \%)$ \\
\hline Unwilling to perform cardiac compression & $0(0.0 \%)$ & $1(4.0 \%)$ \\
\hline
\end{tabular}

$\mathrm{CPR}$, cardiopulmonary resuscitation; $\mathrm{N}$, number of respondents.

\section{DISCUSSION}

Willingness to perform bystander CPR, as well as potential factors affecting the willingness to perform CPR, were analyzed using a questionnaire survey. It is generally accepted that CPR training improves resuscitation attempts when a bystander witnesses a cardiac arrest. In a study on college students, $77 \%$ reported that they were likely to perform CPR or use an external defibrillator in an emergency situation after attending CPR courses. (16) Previous studies conducted in Asians and Caucasians also supported the suggestion that experience of CPR training is closely related to provision of CPR in an emergency. (17-20) Our findings were consistent with these previous studies. The results indicated that about $40 \%$ of the Taiwanese respondents were willing to perform CPR on a stranger, while $89 \%$ were willing to perform CPR on an acquaintance after training. In addition, an increase in willingness to perform hands-only CPR was also noted after training in the present study.

The respondents in the present study reported a much higher likelihood of providing chest compression-only $\mathrm{CPR}$ on a stranger than conventional CPR with mouth-to-mouth ventilation either before $(67.8 \%$ vs. $36.6 \%$, respectively) or after training ( $84.1 \%$ vs. $39.7 \%$, respectively). Similar findings were also reported in previous studies. In a Korean study, more than $70 \%$ of the respondents were willing to provide hands-only $\mathrm{CPR}$ on a stranger after basic life support training, while only $55.7 \%$ of the respondents were likely to perform conventional CPR on a stranger. (19) Large surveys in Japanese subjects also indicated that $50 \%-100 \%$ of participants were likely to perform chest compression-only CPR, but only $10 \%-30 \%$ would perform both chest compression and mouth-to-mouth ventilation on a stranger. (21) Chew et al. also found a low rate of definite "yes" responses regarding willingness to perform chest compression plus mouth-to-mouth ventilation on a stranger in comparison with chest compression only and chest compression with mask-to-mouth ventilation in a Malaysian population. (22) These observations indicated that chest compression may be a more suitable method for bystander CPR than mouth-to-mouth ventilation.

Moreover, it is not surprising that the rates of willingness to perform hands-only CPR and conventional CPR on a family member or an acquaintance were both much higher than those on a stranger in our study. Even with the high proportion of willingness to perform CPR on an acquaintance prior to training, improvements were also noted in willingness to perform both CPR techniques, especially hands-only CPR. The results were similar to those of several other studies. (19,22-24) Our results were also consistent with previous surveys in Australia, Japan, and the USA, in that respondents were less reluctant to perform CPR on an acquaintance than a stranger. $(14,25,26)$
The factors associated with reluctance to perform CPR have been elucidated in many studies. Our study suggested that education level and previous CPR training played roles in willingness to perform CPR. Swor reported that witnessed arrest, trained bystander, bystander with more than high-school education, and arrest occurring in a public location were important predictors of CPR performance. (18) Jackson and Swor found that patients in public locations were more likely to receive bystander CPR. (27) A study conducted in Queensland, Australia, also supported this suggestion. Social demographics affected willingness to perform CPR. Logistic regression analysis indicated that respondents who were male, married or in a de facto relationship, and had received CPR training within 1 year were more likely to perform bystander CPR. (15) In contrast, a study performed in Chicago, USA, did not show any association between CPR performance and socioeconomic status. (28)

Various reasons for unwillingness to perform bystander CPR were addressed in the present study, as well as in previous studies. Before training, the most important barrier to CPR performance was unwillingness to perform mouth-to-mouth ventilation; however, fear of doing further harm was ranked as the major barrier after training. Unlike a previous study in Korea, (19) in which fear of legal liability was the most significant barrier (cited by approximately $50 \%$ of respondents as a major reason for unwillingness to perform CPR even after 
training), our study showed a significant decrease in fear of legal issues after training. This difference may have been due to the inclusion of explanations regarding legal issues associated with CPR in our training program. However, we also found that more respondents claimed to be more afraid of doing further harm to victims post-training compared to pre-training. We supposed that the respondents in our study were more concerned regarding legal issues before training, but after clarification in the training program, respondents began to consider whether they may cause further harm to the victims. Prior to training, respondents indicated the most significant barrier to CPR performance based on their impressions, which were obtained from the media or previous CPR courses. After training, they ranked the most important barrier according to the knowledge that they had obtained from the training course. Therefore, fear of doing further harm was ranked as the greatest obstacle to performing conventional CPR. A survey in Singapore indicated that fear of doing harm was the second greatest barrier to administration of CPR. (29) The respondents who were reluctant to administer CPR reported that fear of disease transmission and mouth-to-mouth ventilation were the most significant barriers to performing conventional CPR. In the USA (30) and
Sweden (31) over $80 \%$ of laypersons reported fear of disease transmission to be a concern, compared to only $18 \%$ of Australian respondents and 7\%-23\% of Japanese high school students and teachers. $(15,21)$ In our study, $32.5 \%$ of the respondents who were not willing to perform conventional CPR indicated that unwillingness to perform mouth-to-mouth ventilation was the greatest barrier. The observed differences between nations may be due to differences in culture, the prevalence of infectious diseases, and the methodologies used in the studies. Our study required respondents to select the single most significant reason for not performing conventional CPR, while other studies provided multiple choices or open questions.

Due to the low willingness to perform mouth-to-mouth resuscitation on a stranger, new CPR training programs for laypersons should be adapted to emphasize the skills of compression-only CPR and the use of automated electrical defibrillators. Further studies will focus on the lay public's awareness of CPR and skills to improve bystander CPR willingness and bystander CPR rate.

Our study had some limitations. First, the questionnaire was not mandatory for course participants, and only 227 of 401
(56.6\%) respondents returned both preand post-training questionnaires. Therefore, our study may not comprehensively reflect the trends in the general population. Second, we did not collect data regarding the underlying reasons for unwillingness to perform mouth-to-mouth ventilation, but we believe that fear of disease transmission may have partially accounted for this barrier. Finally, extending the questionnaire collection period may be helpful to obtain more data.

\section{CONCLUSIONS}

In summary, this study indicated that $\mathrm{CPR}$ training increased the rate of willingness to perform CPR on strangers and acquaintances among the lay public. This study also indicated that fear of doing further harm became the most significant barrier after training. This concern should be addressed in future training programs.

\section{ACKNOWLEDGMENTS}

We would like to thank Dr. Lin Chi-Chun for his work on the statistical analysis and advice.

\section{REFERENCES}

1. Berdowski J, Berg RA, Tijssen JG, Koster RW. Global incidences of out-of-hospital cardiac arrest and survival rates: Systematic review of 67 prospective studies. Resuscitation 2010;81(11):1479-87.

2. Nichol G, Thomas E, Callaway CW, Hedges J, Powell JL, Aufderheide TP, et al. Regional variation in out-of-hospital cardiac arrest incidence and outcome. JAMA 2008;300(12):1423-31.

3. Atwood C, Eisenberg MS, Herlitz J, Rea TD. Incidence of EMS- treated out-of-hospital cardiac arrest in Europe. Resuscitation 2005;67(1):75-80.

4. Rea TD, Eisenberg MS, Sinibaldi G, White RD. Incidence of EMS treated out of-hospital cardiac arrest in the United States. Resuscitation 2004;63(1):17-24.

5. Wang CY, Wang JY, Teng NC, Chao TT, Tsai SL, et al. The Secular Trends in the Incidence Rate and Outcomes of Out-of-Hospital Cardiac Arrest in Taiwan-A Nationwide Population-Based Study. PLoS One 2015;10(4):e0122675.

6. Ritter G, Wolfe RA, Goldstein S, Landis JR, Vasu M, Acheson A, Leighton R, VanderBrug S. The effect of bystander CPR on survival of out-of-hospital cardiac arrest victims. Am Heart J 1985;110(5):932-7.

7. Gallagher EJ, Lombardi G, Gennis P. Effectiveness of bystander cardiopulmonary resuscitation and survival following out-of-hospital cardiac arrest. JAMA 1995;274(24):1922-5.

8. Weston CF, Wilson RJ, Jones SD. Predicting survival from out-of-hospital cardiac arrest: a multivariate analysis. Resuscitation 1997;34(1):27-34.

9. Kida M, Kawamura T, Fukuoka T, Tamakoshi A, Wakai K, Ohno Y, et al. Out-of-hospital cardiac arrest and survival: An epidemiological analysis of emergency service reports in a large city in Japan. Circ J 2004;68(7):603-9.

10. Nichol G, Thomas E, Callaway CW, Hedges J, Powell JL, Aufderheide TP, et al. Regional variation in out-of-hospital cardiac arrest incidence and outcome. JAMA 2008;300(12):1423-31.

11. Atkins DL. Realistic expectations for public access defibrillation programs. Curr Opin Crit Care 2010;16(3):191-5.

12. Nolan RP, Wilson E, Shuster M, Rowe BH, Stewart D, Zambon S. Readiness to perform cardiopulmonary resuscitation: an emerging strategy against sudden cardiac death. Psychosom Med;61(4):546-51. 
13. Axelsson A. Bystander cardiopulmonary resuscitation: would they do it again? J Cardiovasc Nurs 2001;16(1):15-20; quiz 73-4.

14. Jelinek GA, Gennat H, Celenza T, O’Brien D, Jacobs I, Lynch D. Community attitudes toward performing cardiopulmonary resuscitation in Western Australia. Resuscitation 2001;51(3):239-46.

15. Johnston TC, Clark MJ, Dingle GA, FitzGerald G. Factors influencing Queenslanders' willingness to perform bystander cardiopulmonary resuscitation. Resuscitation 2003;56(1):67-75.

16. Hamasu S, Morimoto T, Kuramoto N, Horiguchi M, Iwami T, Nishiyama C, et al. Effects of BLS training on factors associated with attitude toward CPR in college students. Resuscitation 2009;80(3):359-64.

17. Kuramoto N, Morimoto T, Kubota Y, Maeda Y, Seki S, Takada K, et al. Public perception of and willingness to perform bystander CPR in Japan. Resuscitation 2008;79(3):475-81.

18. Swor R, Khan I, Domeier R, Honeycutt L, Chu K, Compton S. CPR training and CPR performance: do CPR-trained bystander perform CPR? Acad Emerg Med 2006;13(6):596-601.

19. Cho GC, Sohn YD, Kang KH, Lee WW, Lim KS, Kim W, et al. The effect of basic life support education on laypersons' willingness in performing bystander hands only cardiopulmonary resuscitation. Resuscitation 2010;81(6):691-4.

20. Nielsen AM, Isbye DL, Lippert FK, Rasmussen LS. Can mass education and a television campaign change the attitudes toward cardiopulmonary resuscitation in a rural community? Scand J Trauma Resusc Emerg Med 2013;21:39.

21. Taniguchi T, Sato K, Fujita T, Okajima M, Takamura M. Attitudes to bystander cardiopulmonary resuscitation in Japan in 2010. Circ J 2012;76(5):1130-5.

22. Chew KS, Yazid MN, Kamarul BA, Rashidi A. Translating knowledge to attitude: a survey on the perception of bystander cardiopulmonary resuscitation among dental students in Universiti Sains Malaysia and school teachers in Kota Bharu, Kelantan. Med J Malaysia 2009;64(3):205-9.

23. Chew KS, Yazid MN. The willingness of final year medical and dental students to perform bystander cardiopulmonary resuscitation in an Asian community. Int J Emerg Med 2008;1(4):301-9.

24. Shibata K, Taniguchi T, Yoshida M, Yamamoto K. Obstacles to bystander cardiopulmonary resuscitation in Japan. Resuscitation 2000;44(3):187-93.

25. Coons SJ, Guy MC. Performing bystander CPR for sudden cardiac arrest: behavioral intentions among the general adult population in Arizona. Resuscitation 2009;80(3):334-40.

26. Omi W, Taniguchi T, Kaburaki T, Okajima M, Takamura M, Noda T, Ohta K, Itoh H, Goto Y, Kaneko S, Inaba H. The attitudes of Japanese high school students toward cardiopulmonary resuscitation. Resuscitation 2008;78(3):340-5.

27. Swor RA, Jackson RE, Compton S, Domeier R, Zalenski R, Honeycutt L, Kuhn GJ, Frederiksen S, Pascual RG. Cardiac arrest in private locations: different strategies are needed to improve outcome. Resuscitation 2003;58(2):171-6.

28. Iwashyna TJ, Christakis NA, Becker LB. Neighborhoods matter: a population-based study of provision of cardiopulmonary resuscitation. Ann Emerg Med 1999;34(4 Pt 1):459-468.

29. Ong ME, Quah JL, Ho AF, Yap S, Edwin N, Ng YY, et al. National population based survey on the prevalence of first aid, cardiopulmonary resuscitation and automated external defibrillator skills in Singapore. Resuscitation 2013;84(11):1633-6.

30. Locke CJ, Berg RA, Sanders AB, Davis MF, Milander MM, Kern KB, et al. Bystander cardiopulmonary resuscitation. Concerns about mouth-to-mouth contact. Arch Intern Med 1995;155(9):938-43.

31. Axelsson A, Thorén A, Holmberg S, Herlitz J. Attitudes of trained Swedish lay rescuers toward CPR performance in an emergency. A survey of 1012 recently trained CPR rescuers. Resuscitation 2000;44(1):27-36. 